\title{
O COMPORTAMENTO DA TAXA SELIC E AS OPERAÇÕES DE INVESTIMENTO E FINANCIAMENTO DE PESSOA FÍSICA NO PERÍODO PÓS-CRISE ECONÔMICA
}

\section{SELIC RATE BEHAVIOR AND INVESTMENT AND FINANCING OPERATIONS FOR INDIVIDUALS IN THE PERIOD POST ECONOMIC CRISIS}

\author{
JOSIANE PONTEL \\ Universidade Franciscana (UFN) \\ Graduada em Administração de Empresas - Universidade Franciscana (UFN) \\ Orcid: https://orcid.org/0000-0003-3537-3192 / E-mail: josianepontel@hotmail.com

\section{PÂMELA AMADO TRISTÃO} \\ Professora Adjunta da Universidade Federal do Rio Grande (ICEAC/FURG) \\ Doutora em Administração pela Universidade Federal de Santa Maria (UFSM) \\ Orcid: https://orcid.org/0000-0002-8408-6942 / E-mail: pamelamado@hotmail.com \\ Endereço: Endereço: Av. Itália, Km 8, s/n. Rio Grande - RS, 96201-900 \\ Instituto das Ciências Econômicas, Administrativas e Contábeis

\section{JULIANA ANDREIA RUDELL BOLIGON} \\ Professora Assistente na Universidade Franciscana (UFN) \\ Mestre em Engenharia da Produção pela Universidade Federal de Santa Maria (UFSM) \\ Orcid: https://orcid.org/0000-0003-3293-7570 / E-mail: julianaboligon@ufn.edu.br
}

\section{RESUMO}

A recente crise econômica enfrentada pelo Brasil, no período de 2014 a 2016, ocasionou, entre outras alterações, o aumento da taxa de juros e da inflação, afetando o Mercado Financeiro. Neste contexto, a presente pesquisa teve como objetivo identificar o comportamento da taxa Selic nos investimentos e financiamentos pessoa física no período pós-crise econômica, em uma instituição financeira privada. O procedimento metodológico utilizado foi de natureza quantitativa e descritiva, dividida em duas etapas, primeiramente foi efetuada a análise de dados no panorama brasileiro das operações de crédito e investimentos pessoa física nas instituições bancárias privadas no período de crise econômica, utilizadas informações mensais do Banco Central em três períodos: P1 - período anterior à crise econômica (2013); P2 - período de crise econômica (2014 a 2015); e P3 - período pós crise econômica (2016 a 2017). Na segunda etapa foi elaborado um estudo de caso em uma instituição financeira privada com análise dos investimentos e financiamentos de pessoa física, onde houve a comparação do período de crise com o que o antecede, foram utilizadas informações anuais de relatórios fornecidos pela instituição nos períodos já citados anteriormente. Os resultaram demonstraram que no período de crise, com a taxa Selic em alta, houve crescimento nos investimentos e a diminuição na concessão de financiamentos. Já no período pós-crise econômica, com a taxa Selic em baixa, os investimentos tiveram redução, e um aumento na a concessão de financiamentos.

Palavras-chave : Mercado financeiro. Taxa Selic. Decisões de investimentos. Concessão de crédito. 


\section{ABSTRACT}

The recent economic crisis faced by Brazil, from 2014 to 2016, caused, among other changes, the increase of the interest rate and inflation, affecting the Financial Market. In this context, the present research had the objective of identifying Selic rate's behavior on personal investment and financing in the post-economic crisis period, in a private financial institution. A quantitative and descriptive study was carried out. In this way the research was elaborated in two stages, firstly the analysis of data in the Brazilian panorama of the credit operations and individual investments in the private banking institutions during the period of economic crisis, using monthly information of the Central Bank in three periods: P1 - previous period to the economic crisis (2013); P2 - economic crisis period (2014 to 2015); and P3 - in the posteconomic crisis period(2016 to 2017). In the second stage, information from a private institution related to individual investments and financing, was investigated comparing the period of crisis with the one preceding it, using annual reports provided by the institution in the periods already cited above. The results showed that in the crisis period, with the Selic rate on the rise, there was growth in investments and the decrease in the granting of financing. In the post-economic crisis period, with the Selic rate down, investments were reduced, and an increase in the granting of financing.

Keywords: Financial market. Selic rate. Investment decisions. Credit acess.

\section{INTRODUÇÃO}

A recente crise econômica vivenciada no Brasil, pode ser considerada a mais profunda e duradoura queda do nível de atividade econômica brasileira desde o término da Segunda Guerra Mundial (OREIRO, 2017) e, originada por uma combinação de fatores domésticos e fatores externos (VARTANIAN; GABE, 2019). Iniciada no segundo trimestre de 2014, com resquícios ainda em 2016, ocasionou, entre outras consequências, o aumento da taxa de juros e da inflação, além do aumento do desemprego, acarretando grande recessão econômica (BARBOSA FILHO, 2017).

Essa situação motivou uma redução considerável da capacidade de crescimento da economia brasileira e no risco de insolvência das finanças públicas. Segundo o Portal Brasil (2017), o grande período de recessão econômica desde o segundo trimestre de 2014 ocasionou a redução do produto per capita brasileiro em cerca de 9\% entre 2014 e 2016, influenciando o aumento do nível de insegurança econômica, devido à sua relação com o mercado, além de influenciar nas previsões de investimentos e no otimismo da população, já que o produto per capita é um indicador de consumo diretamente ligado à renda das pessoas e à taxa de juros.

A recessão resultou, para Nassif (2017), de dois fatores básicos: primeiramente, uma política fiscal altamente expansionista, ocorrida entre os anos de 2012 e 2014, caracterizada por descontrole dos gastos públicos e, em segundo, pela política adotada pelo Conselho de Política Monetária (COPOM) no Banco Central do Brasil (BACEN), que iniciaram, prematuramente, de acordo com o autor, a redução das taxas de juros. Ocorreram então, mudanças no mix e instrumentos de política, como o uso de medidas macro prudenciais monetárias e cambiais e forte redução na taxa Selic (PAULA; PIRES, 2017). Com o intuito de fomentar a economia local, em 2017 o Banco Central do Brasil (BACEN) optou, especificamente, por acelerar a redução da taxa de juros. Houve então, a queda da taxa básica 
de juros (Selic) de 13,75\% em 2014 para 13\% em janeiro de 2017, chegando a 6,65\% em março de 2018.

As mudanças na taxa Selic afetam diretamente a concessão de crédito e a rentabilidade dos investimentos após a crise econômica. Ao elevar a taxa de Selic o custo do dinheiro aumenta no sistema financeiro, fazendo com que pessoas e empresas fiquem desestimuladas a contrair empréstimos, diminuindo a circulação de dinheiro na economia, por outro lado, as aplicações financeiras passam a ser mais atrativas, uma vez que esta taxa também serve como referência para remunerar os títulos públicos federais, a caderneta de poupança e demais modalidades de investimentos de renda fixa ou atreladas a esse indexador (OLIVEIRA et al., 2018). Devido a interligação das variáveis macroeconômicas que conduzem a dinâmica do mercado financeiro, tornam-se evidentes os reflexos do comportamento dessa taxa no cenário macroeconômico afetando, de uma forma geral a concessão de crédito e operações de investimento, especialmente para indivíduos pessoa física. Said et al. (2015) argumentam que eventos econômicos, incluindo crises, tendem a aumentar a aversão ao risco por parte dos indivíduos, os quais passam a dispor de menor disposição a tomar risco.

Tendo em vista o tema relacionado à investimentos e concessão de crédito de pessoa física, a presente pesquisa tem como objetivo identificar o comportamento da taxa Selic e sua relação com a evolução dos investimentos e financiamentos da pessoa física em uma instituição bancária privada no período pós crise financeira. Nota-se a importância da taxa Selic nos investimentos e na concessão de crédito para pessoa física com a instabilidade na economia e no cenário político (OREIRO, 2017), no qual o risco de inadimplência tende a crescer, induzindo as instituições bancárias a modificar as condições para concessão de crédito, influenciando, de maneira contrária, a maior rentabilidade de investimentos associados a alta da taxa de juros, sendo, dessa forma, considerada um bom período para as aplicações financeiras.

Fortuna (2005) afirma ser a taxa Selic um termômetro do custo do dinheiro brasileiro, utilizada para controlar os juros da Economia Brasileira. O COPOM toma decisões para controlar a taxa Selic, pois é ela quem vai favorecer o aumento ou retração do crédito as pessoas e da rentabilidade dos investimentos de renda fixa ou variável.

A relevância do tema estudado é confirmada pelas inúmeras pesquisas realizadas que abordam a situação econômica do país, entre eles o trabalho realizado por Adlas (2012), o qual menciona a relação entre o comportamento da taxa básica de juros e o mercado de capital. Este estudo verificou se houve redução da taxa de juros e aumento do mercado de crédito no Brasil, onde foi constatado que a diminuição da taxa básica de juros Selic tem forte influência na política bancária, instigando o volume de crédito direcionado para economia brasileira. Além deste, Nakano (2005) afirma, por meio de seus resultados que, ao elevar a taxa de juros, os portadores de dívida pública ficam mais ricos e bancos também têm seus ativos e suas receitas elevados.

A presente pesquisa se diferencia das demais por abordar o recente período de crise econômica vivenciado no Brasil, tendo como motivação de pesquisa o fato de que diante do cenário da crise econômica dos anos de 2014 à 2016, torna-se necessário obter conhecimento das principais modalidades de investimentos e financiamentos disponíveis no mercado brasileiro, proporcionando aos agentes, sejam eles superavitários ou deficitários, um suporte para que tomem decisões de forma consciente e fundamentada na hora de investir. Dessa maneira, a presente pesquisa justifica-se, por ter o intuito de esclarecer a importância da taxa Selic em período de crise econômica, onde a economia do país está em recesso devido a altas taxas de juros e inadimplência, no que tange à investimentos e financiamentos. 


\section{O MERCADO FINANCEIRO BRASILEIRO}

O mercado financeiro é formado por instituições que se dedicam ao trabalho de propiciar condições suficientes para a manutenção de um fluxo de recursos entre poupadores (superavitários) e credores (deficitários), sendo considerado um elemento importante no crescimento econômico, uma vez que permite a elevação ou diminuição das taxas de juros de poupança e investimentos (OREIO, 2017).

Nesse ambiente, as instituições financeiras são grandes influenciadores no mercado, e podem ser classificadas em: a) bancárias, sendo as representadas pelos bancos comercias e bancos múltiplos nas quais existem trocas de moeda por meio de depósitos à vista e também transações com ativos financeiros (empréstimos e financiamentos) e; b) por instituições não financeiras as quais não estão autorizadas a receber depósito à vista, que trabalham com ativos não monetários, como letras de câmbio, debêntures, entre outros.

Já os órgãos contribuintes do mercado financeiro são separados em dois subsistemas: o normativo, que é fiscalizador e regulamentador e, o de intermediação financeira, responsável pelas operações financeiras. O subsistema normativo é composto pelos órgãos principais: Conselho Monetário Nacional (CMN), Banco Central do Brasil (BACEN), Comissão de Valores Mobiliários (CVM) e Banco Nacional de Desenvolvimento Econômico e Social (BNDES) (MELLAGI FILHO; ISHIKAWA, 2003).

De acordo com Fortuna (2005) o CMN tem como principal objetivo estabelecer condições para a emissão de papel-moeda, coordenar e controlar as políticas monetárias, estabelecer aplicações de recursos com o intuito de atender aos interesses econômicos e sociais do país. Este órgão possui influência sobre as taxas de juros e a poupança, podendo afetar o rendimento de certas aplicações financeiras. O BACEN, por sua vez, é o banco fiscalizador e disciplinador do mercado financeiro, responsável por acompanhar, analisar e intervir em qualquer ameaça de instituições financeiras que possam danificar o sistema bancário nacional; ele também participa nas negociações de títulos públicos emitidos pelo Tesouro Nacional, regulando a oferta e a demanda da moeda (ASSAF NETO, 2011). Fortuna (2005) ainda explica que a CVM, é o órgão que regula e fiscaliza o mercado de capitais, principalmente de capital aberto. Este órgão é focado na fiscalização, disciplina e desenvolvimento do mercado de valores mobiliários, seu principal objetivo é o fortalecimento do mercado de ações e dos demais valores mobiliários. O BNDES, por sua vez, é uma instituição pública federal, seu principal objetivo é o financiamento de longo prazo e a realização de investimentos em todos os segmentos da economia, no âmbito social, regional e ambiental.

Assim, a intermediação financeira ocorre e desenvolve-se com base em quatro subdivisões estabelecidas para o mercado financeiro que são: mercado monetário, mercado de crédito, mercado de capitais e mercado cambial. As subdivisões servem de referência para o estudo do mercado financeiro, pois são as referências para diversas negociações financeiras. O Quadro 01 apresenta as principais ramificações do mercado financeiro e suas principais características e prazo de negociação.

Quadro 1 - Estrutura do mercado financeiro

\begin{tabular}{|c|c|c|}
\hline Mercados & Atuação & Prazos \\
\hline Monetário & $\begin{array}{c}\text { Controle dos meios de pagamento (liquidez da } \\
\text { economia). }\end{array}$ & Curtíssimo prazo e prazos curtos \\
\hline Crédito & Créditos para consumo e capital de giro & Curto e médio prazo \\
\hline Capitais & Investimentos e outras operações & Médio e longo prazos \\
\hline Cambial & Conversão de moedas & A vista e curto prazo \\
\hline
\end{tabular}

Fonte: Adaptado de Assaf Neto (2011, p. 57).

RGO - Revista Gestão Organizacional, Chapecó, v. 13, n. 2, p. 123-141, maio/ago. 2020. 
Conforme exposto, no mercado financeiro e em suas quatro subdivisões ocorre o funcionamento das principais operações de financiamento e de investimentos de renda fixa e variável. Basicamente, o mercado financeiro é o mercado de tomadores de empréstimos e de investidores (MELLAGI FILHO e ISHIKAWA, 2003). No que tange aos investimentos, os ativos podem ser classificados como de renda fiz ou variável, conforme exposto no tópico seguinte.

\subsection{INVESTIMENTO EM RENDA FIXA}

Os ativos de renda fixa são investimentos considerados seguros, sendo muitos deles cobertos pelo Fundo Garantidor de Crédito (FGC), que apresentam um retorno fixo periódico. Esses investimentos tendem a ser populares durante períodos de altas taxas de juros, quando os investidores procuram "garantir" altos retornos financeiros. Dentre eles, o Certificado de Depósito Bancário (CDB), Letras de Crédito Imobiliário (LCI), Caderneta de Poupança e Tesouro Direto.

Fortuna (2005) afirma que o investimento de CDB é um título emitido pelos bancos comerciais, bancos de desenvolvimento e bancos múltiplos, utilizado para a sua própria capitalização. Através destes, a instituição emissora dos títulos capta recursos para financiar suas atividades de crédito como empréstimos, financiamentos, entre outros. São títulos de renda fixa que podem ter rendimentos pré-fixados, pós-fixados ou flutuantes (atrelada à variação de algum índice, como Certificado de Depósito Interbancário - CDI, por exemplo). Segundo Kerr (2011) nas aplicações de CDB, o Imposto de Operações Financeiras (IOF) incide quando efetuado o resgate inferior a trinta dias. Já a alíquota de Imposto de Renda (IR) é variável e depende do prazo de aplicação, sendo descrente em relação a data do investimento.

As LCl's, por sua vez, são, conforme Lovato (2011) papéis lastreados por créditos imobiliários garantidos por hipoteca ou alienação fiduciária de imóveis considerados títulos de renda fixa que podem ter rendimentos pré-fixados ou pós-fixados referenciados à taxa Selic e podem ser emitidas com juros prefixados, pós-fixados, com prazo mínimo de 180 dias e máximo 24 meses. O vencimento da $\mathrm{LCl}$ varia de acordo com o indexador que possui e pode ser de 36 meses quando atualizada mensalmente, 12 meses quando atualizada anualmente ou 60 dias para demais casos. Ainda sobre a LCl, a Central de Custódia e Liquidação Financeira de Títulos Privados - CETIP (2017) afirma que os valores investidos não podem ser resgatados a qualquer momento.

A caderneta de poupança é a aplicação mais simples e tradicional, segundo relatório do BACEN de maio de 2018, sua remuneração encontra-se em $0,37 \%$ ao mês, aplicada sobre os valores atualizados da Taxa Referencial (TR) na data de aniversário da aplicação (ou seja, no dia em que foi efetuado o depósito) (FORTUNA, 2005). Já as aplicações em Tesouro Direto são um sistema pelo qual o investidor pode comprar títulos do governo federal pela internet. Estes títulos têm o objetivo de captar recursos para o financiamento da dívida pública federal e para financiar investimentos do Governo, nas áreas de educação e saúde (LUQUET, 2007).

Após apresentadas as diversas e principais modalidades de investimento existentes no mercado de ativos de renda fixa brasileiro, é importante ser abordado os investimentos de ativos em que seu valor não pode ser dimensionado no momento da aplicação, os investimentos em renda variável.

\subsection{INVESTIMENTO EM RENDA VARIÁVEL}

De acordo com Lovato (2011), nos investimentos de renda variável, o montante aplicado sofre oscilações tanto positivas quanto negativas, ou seja, o retorno de capital não 
pode ser dimensionado no momento da aplicação. Entre as opções de investimentos deste tipo tem-se: ações, fundos de investimentos e derivativos.

As ações são constituídas por títulos representativos da menor fração do capital social de uma empresa, sendo o acionista considerado um coproprietário com direito a participação nos lucros e resultados da companhia. As ações podem ser: (a) ordinárias (ON), que garantem direito a voto nas assembleias da companhia, tendo o titular do investimento o direito de intervir no rumo da organização e, (b) preferenciais (PN), que concedem preferência na distribuição de dividendos ou em caso de liquidação da organização, no reembolso do capital investido e no recebimento de dividendos (ASSAF e LIMA, 2011).

Para Fortuna (2005) os principais fundos de investimento em renda variável são: i) referenciados, ii) multimercado, iii) cambial, e iv) dívida externa. Os fundos classificados como referenciados, possuem uma carteira que tem por objetivo acompanhar o desempenho de um índice referencial para a rentabilidade do fundo, neste fundo deve-se investir no mínimo $80 \%$ em títulos públicos federais ou em títulos de renda fixa privados de baixo risco de crédito. Esse tipo de fundo tem $95 \%$ dos ativos da carteira em ativos que acompanham a variação do indicador de desempenho.

Já os fundos multimercado, envolvem vários fatores de risco, pois podem combinar investimentos em renda fixa, câmbio, ações e outros. O fundo cambial referente ao dólar e as aplicações em fundos em dívida externa, no mínimo $80 \%$ do seu patrimônio devem ser aplicados em títulos brasileiros negociados no mercado internacional, o restante pode ser aplicado em outros títulos negociados no exterior (FORTUNA, 2005).

Os investimentos em derivativos, por sua vez, conforme Carvalho (1999) são definidos como instrumentos financeiros cujos valores dependem dos valores de outro ativo. Existem vários tipos de derivativos, sendo os mais conhecidos: a) o mercado termo a termo, no qual duas partes assumem um compromisso de compra ou venda para negociação de um determinado ativo financeiro em uma data futura, b) o mercado futuro é parecido com o mercado termo, porém, ambas as partes não são vinculadas, c) o mercado de opções, no qual são negociados direitos de compra ou venda de um lote de ações, que dá a seu titular o direito sobre algo, mas não uma obrigação e, a seu vendedor, uma obrigação futura, caso solicitado pelo comprador da opção.

\subsection{AS MODALIDADES DE CRÉDITO PARA PESSOA FÍSICA}

As modalidades de crédito são produtos oferecidos por bancos para suprir possíveis defasagens de caixa do cliente, podendo este ajustar o valor da prestação mensal a sua capacidade de pagamento (SILVA, 2008). Complementarmente, Kerr (2011) afirma serem os principais instrumentos de crédito no Brasil: cheque especial, cartão de crédito, crédito consignado, crédito pessoal, e crédito direto ao consumidor (CDC).

Para Oliveira (2010) o crédito de cheque especial é um valor-limite vinculada a conta corrente. É uma modalidade de crédito "extra" disponibilizado para correntistas, podendo ser movimentado a qualquer momento, no qual os juros pagos por sua utilização são calculados diariamente sobre o saldo devedor.

Além destes, o cartão de crédito, utilizado em grande escala atualmente permite ao seu titular um limite de crédito para aquisição de bens e serviços em que seus usuários podem efetuar e compras até o valor desse limite. Algumas compras podem ser feitas em parcelas, sem que haja a incidência de juros e encargos e as despesas realizadas no período, geralmente de um mês, são consolidadas em uma única fatura para pagamento em determinada data (ASSAF NETO, 2011). 
Os empréstimos em consignação, são segundo Fortuna (2005), empréstimos com o desconto das prestações direto na folha de pagamento, os quais normalmente, oferecem taxas de juros menores. O menor juro é resultado do baixo risco de inadimplência assumido pelos bancos, já que o pagamento é feito diretamente pela empresa. Já em relação ao crédito pessoal, Vieceli (2011) argumenta ser a modalidade destinada a pessoa física que pode ou não ter garantia real e o prazo varia entre até 60 meses, em geral, devendo a prestação mensal do compromisso de o empréstimo ser inferior ou igual a $30 \%$ da renda líquida do cliente. As atuais taxas do crédito pessoal segundo o Portal Brasil (2017) foram reduzidas de 7,99\% para 7,89\% ao mês, no segundo semestre de 2017, devido à redução da Selic.

Por sua vez o CDC, conforme Kerr (2011), é a modalidade de financiamento concedido às pessoas para aquisição de veículos, cujo crédito destina-se para a compra de um bem, o qual serve como garantia na instituição bancária, ficando o bem adquirido alienado à instituição até a liquidação do crédito. O prazo de financiamento varia de 3 a 24 meses e, geralmente, financia de 50 a $80 \%$ do valor do bem, as taxas são pré-fixadas, ou seja, já estipuladas no momento do financiamento, não ocorrendo variação nos valores com o decorrer dos meses (FORTUNA, 2005).

\subsection{AS TAXAS DE JUROS NO BRASIL}

A taxa de juros é o instrumento utilizado pelo Banco Central para manter a inflação sobre controle e para estimular a economia. As taxas de juros mais utilizadas no mercado financeiro do Brasil são: Taxa Referencial (TR), Taxa Básica Financeira (TBF), Taxa de Juros de Longo Prazo (TJLP) e Taxa Selic (ASSAF e LIMA, 2011). Ainda de acordo com o autor, a TR é apurada e anunciada mensalmente pelo Governo. Sua forma de cálculo é feita pela remuneração média das aplicações financeiras em CDB. Já a TBF tem como objetivo alongar o perfil das aplicações em títulos, pois sua rentabilidade é maior que a TR. A TJLP possui a finalidade de estimular os investimentos nos segmentos de infraestrutura e consumo.

A Selic, considerada referência do mercado, exerce forte influência sobre a dívida pública, oferta de crédito, inflação, entre outros. A elevação da taxa de juros gera a diminuição do consumo e do investimento, como consequência ocasiona a diminuição dos preços dos produtos o que causa queda nos índices de inflação. Dessa forma, é utilizada pelo governo como mecanismo monetário para combater a inflação, sendo utilizada para estabelecer o custo do dinheiro no mercado financeiro e ser referência para as demais taxas de juros do mercado.

O COPOM fixa periodicamente o objetivo para a taxa Selic para fins de política monetária, sendo esta válida durante o período compreendido entre suas reuniões ordinárias. O objetivo de aumentar ou diminuir a taxa Selic é relacionado a situação econômica do país. Conforme Fortuna (2005), a Selic, representa a taxa pelo qual o BACEN compra e vende títulos públicos federais ao fazer sua política monetária, estando associada ao comportamento dos títulos ou financiamentos. Dessa forma, conforme a taxa Selic aumenta, os investimentos possuem maior rentabilidade e os financiamentos maiores juros, ou seja, os financiamentos terão juros mais agressivos aos consumidores pois são referenciados a taxa Selic, quanto maior essa taxa, maiores os juros cobrados; já nos investimentos atrelados à Selic, maior a rentabilidade.

Alguns fatores são considerados relevantes para a determinação da taxa Selic, e incluem, mas não se limitam ao percentual de depósitos compulsórios exigidos pelo BACEN, a carga tributária incidente nos empréstimos, o risco de inadimplência e o grau de concorrência existente no mercado financeiro (KERR, 2011). 


\subsection{A CRISE ECONÔMICA OCORRIDA NO BRASIL NOS ANOS DE 2014 A 2016}

A recente crise econômica é o resultado de um conjunto de choques de oferta e de demanda, os quais foram ocasionados por erros de política econômica, cometidos principalmente no período em que foram adotadas políticas que formaram a Nova Matriz Econômica (NME) (BARBOSA FILHO, 2017). Neste período, as políticas fiscais e expansionistas, ao fomentar o consumo e reduzir o desemprego, acarretaram a longo prazo, no aumento da inflação e, consequente, na desvalorização da moeda local perante o dólar.

Objetivando conter a inflação por meio da redução da moeda, o COPOM, então, elevou em 29.07.2015 a taxa Selic à 14,25\% ao final ano. Esse aumento dificultou às pessoas físicas e jurídicas o acesso a capital de terceiros já que o custo do capital se elevou de maneira considerável, desestimando o mercado interno e, diminuindo a circulação de moeda no país (OLIVEIA et al., 2018)

A crise atingiu todos os setores da economia comprometendo o emprego e a renda da população e o produto per capita brasileiro caiu de, aproximadamente, 9\% entre 2014 e 2016. Para Pignata e Carvalho (2015), a crise ocorrida ainda causou impactos financeiros e danos na economia, gerando desequilíbrio entre produção e consumo, desempregos e falências de empresas, afetando assim, toda a sociedade. Os efeitos de crise econômicas podem variar de acordo com as características de cada país de origem, como maior dependência do mercado internacional, dívida e políticas econômicas de expansão (VARTANIAN e GABE, 2019).

Para Paula e Pires (2017), entre 2010 e 2014, o governo apostou que a mudança no mix de política econômica com a redução da Selic e desvalorização cambial, a NME, adicionada às isenções fiscais seriam aceitáveis para impulsionar a oferta e a demanda agregada de bens. Porém, procuraram implementar medidas com a finalidade de estimular o crescimento, como a extensão da desoneração de folha de pagamento para mais setores. Tal ação, contudo, não foi bem coordenada e necessitou de consistência: a adoção de uma política fiscal anticíclica se justificava face ao baixo performance da economia, mas veio morosamente, privilegiou isenções fiscais ao invés de investimentos públicos e foi mal comunicada aos agentes. Para compensar a política monetária, o governo continuou a expandir os gastos públicos e, em consequência, o resultado fiscal primário trouxe queda no PIB de $1,7 \%$, em 2013, para -0,6\%, em 2014.

A crise econômica é considerada como uma das etapas do ciclo econômico, aliada juntamente à superprodução, recessão e depressão, associada ao decréscimo do PIB e altas taxas de juros. Pode-se afirmar, portanto, serem períodos em que a economia de um país passa por grandes perturbações, tornando-se impossibilitado de controlar fatores como a inflação e taxa de juros em alta, que causam a escassez na produção, na comercialização e no consumo de produtos e serviços, aumento do desemprego e pobreza (PIGNATA; CARVALHO, 2015).

Kringger e Panichi (2016) relatam que, além da recessão financeira enfrentada pelo país, há uma forte crise política instaurada, sendo ela uma das principais responsáveis pelo atual desequilíbrio da economia. São vários possíveis e prováveis motivos que levaram o Brasil a uma crise econômica, sendo a falta de investimentos em infraestrutura, fazendo o Brasil perder competividade dentro e fora do país, pois a política vem prejudicando todos os setores como educação, saúde e economia. 


\section{METODOLOGIA}

Este estudo teve como objetivo geral identificar o comportamento da taxa Selic e sua relação com a evolução dos investimentos e financiamentos de pessoa física em uma instituição bancária no período pós crise econômica. Para tal foi delineada uma pesquisa de natureza quantitativa e abordagem descritiva.

A pesquisa quantitativa, de acordo com Malhotra (2012), tem como objetivo quantificar os dados e generalizar os resultados da amostra para a população de interesse. Pesquisas dessa natureza, geralmente, aplicam análise estatística para melhor interpretação dos dados obtidos (HAIR, 2005). Quanto à abordagem, o presente estudo é classificado como descritivo, característico em pesquisas que possuem como objetivo principal a descrição das particularidades de uma população ou fenômeno, bem como o estabelecimento de relações entre variáveis (GIL, 2002).

Ainda, destaca-se que este estudo se amparou em dados secundários coletados de relatórios do BACEN e da instituição estudada, os quais foram submetidos às técnicas estatísticas, trabalhadas em percentuais. Esses dados foram obtidos de relatórios internos da instituição pesquisada e do Banco Central, em três períodos: período que antecede a crise econômica, o período de crise econômica e o período pós. Dessa forma, a análise da influência da taxa Selic em financiamentos e investimentos de pessoa física foi elaborada em duas etapas. Primeiramente foi efetuada a análise de dados no panorama brasileiro das operações de crédito e investimentos pessoa física nas instituições bancárias privadas no período de crise econômica. Objetivando a comparação do período de crise com o que o antecede, foram utilizadas informações mensais do Banco Central em três períodos: P1 - período que antecede a crise (2013); P2 - período de crise econômica (2014 a 2015); e, P3 - período pós-crise econômica (2016 a 2017).

A segunda etapa objetivou uma análise mais acurada acerca da instituição bancária do presente estudo, para tanto, foram analisados dados provindos de relatórios de concessão de crédito e investimentos de pessoa física da instituição bancária privada. Tal análise tem como foco a observação do comportamento das operações pessoa física, sua comparação com os dados no cenário brasileiro, comentados recentemente, além do estudo das alterações da taxa Selic, observadas no período recente, sob essas operações.

Para análise e tabulação dos dados foram utilizados softwares como o Excel e Statistical Product and Service Solutions (SSPS), os quais tornaram possível a análise gráfica.

\section{ANÁLISE DOS RESULTADOS}

\subsection{TAXA SELIC E A CONCESSÃO DE CRÉDITO E INVESTIMENTOS NO CENÁRIO NACIONAL}

Essa subseção relata a evolução da taxa Selic, e o desenvolvimento das principais modalidades de créditos e investimentos segundo o BACEN. Por meio de dados obtidos no BACEN, a Tabela 1 apresenta as principais modalidades de financiamentos e investimentos para pessoa física, assim como as alterações na taxa Selic no período anterior à crise econômica (2013), período de crise econômica (2014 a 2016) e pós crise econômica (2017) no cenário nacional.

Conforme exposto, é possível notar certa oscilação no comportamento da taxa de juros, sendo observado um aumento da taxa Selic nos anos de crise econômica, 2014, 2015 e 2016 , se comparado ao ano anterior a ela e, tendo maior aumento em 2015, encerrando o ano em $14,15 \%$. No período após a crise, é possível observar a retração na taxa de juros, a 
qual caiu para 7\%. Para Barbosa (2017) este comportamento ocorre quando a inflação está em alta e o Banco Central eleva a Selic na expectativa de encarecer o crédito e retrair o consumo e, com isso, influenciar na queda da inflação. O aumento/redução da taxa Selic é um instrumento utilizado como política monetária, cuja fixação pode ocasionar estímulos ao consumo na economia ou pressões inflacionárias, sendo, portanto, avaliada com cautela pelo Copom (BARBOSA 2017). Quando as estimativas para a inflação estão em linha com as metas predeterminadas pelo CMN, o BACEN reduz os juros, fato ocorrido em 2017, quando a Selic teve queda expressiva, fechando o ano em $7,0 \%$.

Tabela 1- Taxa Selic e operações de financiamento e investimento no cenário Nacional.

\begin{tabular}{|c|c|c|c|c|c|}
\hline & \multirow{2}{*}{$\begin{array}{c}\begin{array}{c}\text { Anterior à } \\
\text { crise }\end{array} \\
2013\end{array}$} & \multicolumn{2}{|c|}{ Período de crise } & \multicolumn{2}{|c|}{ Posterior à crise } \\
\hline & & 2014 & 2015 & 2016 & 2017 \\
\hline Evolução da taxa Selic & $7,25 \%$ & $11,75 \%$ & $14,15 \%$ & $13,65 \%$ & $7,0 \%$ \\
\hline Crédito à pessoa Física: & & & & & \\
\hline Crédito pessoal & $14.5 \%$ & $11.2 \%$ & $7.6 \%$ & $0.18 \%$ & $-5.78 \%$ \\
\hline Crédito consignado & $17.5 \%$ & $13.7 \%$ & $8.6 \%$ & $6.7 \%$ & $5.66 \%$ \\
\hline Financiamento de veículo & $-0.2 \%$ & $-4.5 \%$ & $-12.5 \%$ & $-13.31 \%$ & $-7.51 \%$ \\
\hline Cartão de crédito & $14.2 \%$ & $11.2 \%$ & $7.4 \%$ & $6.99 \%$ & $7.9 \%$ \\
\hline Cheque especial & $7.4 \%$ & $5.0 \%$ & $0.2 \%$ & $-2.3 \%$ & $-3.2 \%$ \\
\hline Imobiliário & $32 \%$ & $28.0 \%$ & $15.7 \%$ & $9.88 \%$ & $7.8 \%$ \\
\hline Rural & $26 \%$ & $22.3 \%$ & $15.2 \%$ & $16.2 \%$ & $18.5 \%$ \\
\hline $\begin{array}{l}\text { Investimentos a pessoa física: } \\
\text { Poupança }\end{array}$ & $20,7 \%$ & $10,82 \%$ & $-0,92 \%$ & $1,27 \%$ & $1,56 \%$ \\
\hline Deposito a prazo & $7,4 \%$ & $-7,29 \%$ & $0,18 \%$ & $12,63 \%$ & $17,82 \%$ \\
\hline $\mathrm{LCl}$ & $8,6 \%$ & $66,81 \%$ & $27,75 \%$ & $-1,32 \%$ & $1,27 \%$ \\
\hline Renda variável & $8,34 \%$ & $36,03 \%$ & $37,81 \%$ & $-20,38 \%$ & $-2,07 \%$ \\
\hline
\end{tabular}

* Para fins de comparação, não são apresentados os valores absolutos, mas sim o comportamento de aumento ou redução com base no ano anterior.

Fonte: Elaborado pela autora com base em dados do BACEN no período de 2013 a 2017.

Assim como observado na taxa de juros, as operações de crédito para pessoa física também sofreram alterações ao longo do período analisado. Assaf Neto (2011) justifica esse comportamento devido à influência da Selic na concessão de crédito, devido ao fato de os créditos estarem atrelados à taxa de juros Selic, conduzindo o mercado financeiro. Tornamse, portanto, evidentes os reflexos do comportamento da taxa de juros no cenário macroeconômico de forma geral, afetando, a concessão de crédito para indivíduos pessoa física.

Sendo assim, com a taxa Selic em alta, o crédito à pessoa física teve reduzida a sua utilização a partir de 2014, devido as suas altas taxas de juros para concessão, período este em que a Selic estava em ascensão. Observa-se uma drástica queda na utilização do crédito pessoal, de 14,5\% em 2013 para -5,78\% em 2017, o mesmo ocorreu com o crédito consignado que em 2013 estava com crescimento de 17,5\% reduziu para 5,66\% em 2017. A utilização do cartão de crédito, por sua vez, apresentou redução de 14,2 \% para 6,99\% em 2016, e um leve aumento em 2017, finalizando em 7,9\%. Já o cheque especial teve uma grande queda sendo 7,4 \% em 2013 e reduzindo-se em -3,2\% em 2017, devido a ser a linha de crédito que possui a maior taxa de juro cobrada, perdeu somente para financiamento de veículo que em 2013 teve um aumento na utilização de 12,5 \% chegando à -7,51 \% em 2017.

O crédito imobiliário caiu de 32\% em 2013 para 7,8\% em 2017, isso ocorreu devido à instabilidade econômica e alta taxa de juros. Em consulta ao site globo.com, a principal explicação para o ritmo menor de queda das taxas do crédito imobiliário, mesmo com a redução da taxa Selic, é o fato de se tratar de um financiamento de longo prazo, que costuma 
variar de 20 a 30 anos. No crédito Rural houve uma redução desde 2013, onde estava com crescimento de 26\%, chegando a 15,2\% em 2015, em 2016 começou a ter crescimento novamente, fechando em 2017 com 18,5\% de crescimento. Em consulta ao Banco Central, este crescimento teve como base o aumento dos investimentos com a agricultura, como o de construção de armazéns, indicando assim a retomada da confiança dos produtores na agropecuária após a crise econômica.

Em termos de investimentos, o período analisado, por abranger subperíodos anterior, durante a crise e, após sua duração, permite a identificação de diferentes tendências, tanto de aumento quando de redução das modalidades analisadas, haja visto que, para Felipe et al. (2017), a tolerância ao risco e as expectativas de retornos destes tendem a reduzir em período de crise, diferentemente da expectativa após a crise, em que, para Hoffmann et al. (2013) a percepção de risco dos investidores tenderia a retornar ao estado original. Os resultados obtidos, no entanto, sugerem que a percepção de risco não é uniforme entre os investidores durante a crise, haja visto que foram observadas oscilações, tanto positivas, quando de decréscimo em algumas modalidades de investimento. Tal fato pode estar atrelado, igualmente, ao conhecimento acerca das modalidades de investimentos o que induz a percepção de possível perda de capital em períodos determinados, já que a literatura sugere a existência de limitações na escolha de novos produtos de investimentos devido à falta de conhecimento de finanças.

Nos investimentos à pessoa física nota-se que as aplicações em poupança tiveram um decréscimo nos investimentos desde 2013, chegando a 1,56\% em 2017. Dias (2016) afirma que as aplicações em poupança tiveram seus retornos mensais médios líquidos inferiores aos observados no CDI, sendo que o retorno total da caderneta de poupança foi inferior aos outros investimentos, influenciando a migração dos valores investidos em poupança para outros investimentos com maior retorno. Portanto, assim como os retornos médios mensais, observa-se a redução dos investidores que escolhem a poupança como investimento e, devido à uma rentabilidade baixa em comparação aos outros investimentos atrelas a Selic.

As aplicações em depósito a prazo foram as menos utilizadas para investimentos no período de crise econômica, ocorrendo redução de -7,29\% em 2014 e de 0,18\% em 2015. Já no período pós-crise econômica, houve aumento de $12,63 \%$ e 17,82\%. Os investimentos em LCl tiverem um acentuado crescimento no ano de 2014 e 2015, de 66,81\% e 27,75\%, respectivamente, isso ocorreu segundo Dias (2016), porque as aplicações em LCl aumentam, e também a acessão do credito imobiliário em 2014, ano que apresentou acréscimo de 66,81\% os investimentos em $\mathrm{LCl}$, pois estes recursos captados são direcionados para concessão de imobiliária, porém nota-se que houve o decréscimo nos próximos anos de 2016 e 2017.

É possível observar que, no período de crise econômica, os investimentos em renda variável foram considerados as melhores opções pelos investidores, com um acréscimo de 36,03\% em 2014 e 37,81 em 2015. Para Oliveira (2010) os investidores com perfil conservador, aplicadores em renda fixa, poupança ou CDB, passam a buscar na renda variável a possibilidade de maiores ganhos, tendo em vista o crescente histórico da sua rentabilidade. Ocorreu um decréscimo nos investimentos em renda variável muito significado, no período pós-crise econômica e com a queda da taxa Selic, sendo no ano de 2016 -20,38\% e em 2017 $2,07 \%$. 


\subsection{TAXA SELIC E A CONCESSÃO DE CRÉDITO E INVESTIMENTOS EM UMA INSTITUIÇÃO BANCÁRIA}

A segunda etapa do estudo consistiu em realizar o estudo do comportamento das modalidades de financiamento e investimento no período anterior à crise econômica (2013), período de crise econômica (2014 a 2016) e pós-crise econômica (2017) na instituição estudada.

Conforme exposto, o crédito pessoal apresentou crescimento em todo período de crise econômica, destacando o maior crescimento em 2013 de 14,7\% e em 2017 de 8,8\%. Já em relação do cartão de crédito nota-se que teve o crescimento mais contínuo entre as concessões de crédito, não sofrendo muitas alterações, sendo que em 2013 obteve 10,4\% e em 2017 9,5\%. Segundo Hubert (2016), o cartão de crédito consiste em um instrumento que facilita as negociações do cliente com a empresa, com estas facilidades, quase a totalidade dos consumidores afirmam se tornarem mais suscetíveis às comprar em lojas que aceitem cartões (de débito ou de crédito).

Tabela 2- Operações de financiamento e investimento em uma instituição bancária privada.

\begin{tabular}{|c|c|c|c|c|c|}
\hline & \multirow{2}{*}{$\begin{array}{c}\begin{array}{c}\text { Anterior à } \\
\text { crise }\end{array} \\
2013 \\
\end{array}$} & \multicolumn{2}{|c|}{ Período de crise } & \multicolumn{2}{|c|}{ Posterior à crise } \\
\hline & & 2014 & 2015 & 2016 & 2017 \\
\hline Crédito à pessoa Física: & & & & & \\
\hline Crédito pessoal & $14,7 \%$ & $8,2 \%$ & $8,1 \%$ & $2,4 \%$ & $8,8 \%$ \\
\hline Crédito consignado & $14,8 \%$ & $13,7 \%$ & $8,8 \%$ & $5,5 \%$ & $8,2 \%$ \\
\hline Financiamento de veículo & $-4.9 \%$ & $-6,6 \%$ & $-13 \%$ & $-11,1 \%$ & $9 \%$ \\
\hline Cartão de crédito & $10,4 \%$ & $10,9 \%$ & $7,98 \%$ & $8,6 \%$ & $9,5 \%$ \\
\hline Cheque especial & $7,7 \%$ & $4,7 \%$ & $0,9 \%$ & $-5,5 \%$ & $-4,0 \%$ \\
\hline Imobiliário & $31,1 \%$ & $27,3 \%$ & $15 \%$ & $5.8 \%$ & $6,1 \%$ \\
\hline Rural & $15,9 \%$ & $15,7 \%$ & $6,4 \%$ & $-11,5 \%$ & $-5,6 \%$ \\
\hline $\begin{array}{l}\text { Investimentos a pessoa física: } \\
\text { Poupança }\end{array}$ & $15,35 \%$ & $13,1 \%$ & $15,22 \%$ & $5,23 \%$ & $-2,3 \%$ \\
\hline Deposito á prazo & $8,66 \%$ & $23,33 \%$ & $25,89 \%$ & $6,44 \%$ & $8,2 \%$ \\
\hline $\mathrm{LCl}$ & $11,32 \%$ & $75,95 \%$ & $54,42 \%$ & $32,82 \%$ & $24,66 \%$ \\
\hline Renda variável* & - & - & - & - & - \\
\hline
\end{tabular}

Fonte: Elaborado pela autora com base em relatórios do Banco estudado no período de 2013 a 2017.

*Informação não disponível pela instituição estuda.

Já o crédito para financiamento de veículo apresentou queda de $-4,9 \%$, em 2013, chegando a -11.1\%, em 2016 e, boa recuperação no ano de 2017 (período pós-crise econômica) com crescimento de $9 \%$. O crédito pessoal, teve crescimento em todo período de crise econômica, destacando o maior crescimento, em 2013, de $14,7 \%$ e, no período pós crise econômica retomando o crescimento em $8,8 \%$. Já o crédito consignado apresentou redução na concessão a partir de 2015 com 8,8\% e, em 2016, 5,5\% e retomando o crescimento em 2017 com 8,2\%. Nota-se que estas linhas de crédito retomam o crescimento no período póscrise economia pois, segundo Passos (2007), os segmentos de linha de crédito que apresentaram maior sensibilidade à variação da taxa de juros, lideram a recuperação do período pós crise econômica, como é o caso do financiamento de veículo e o crédito pessoal e consignado, devido à maior procura e necessidades dos consumidores

Além destes, observou-se a utilização do cheque especial apresentou queda considerável em sua utilização, visto que no período anterior à crise econômica, em 2013, apresentava $7,7 \%$ de crescimento, chegando ao período pós crise econômica com $-4 \%$. Já o crédito imobiliário teve uma redução significativa na evolução da sua concessão de crédito desde 2013. Sant'Anna, Junior e Araújo (2009) relatam que os resultados dos investimentos 
em crédito imobiliário estão relacionados, com a diminuição dos investimentos residenciais e com o receio de comprometimento da renda familiar, visto que o Brasil passa por momentos políticos conturbados, afetando assim a recuperação da confiança dos consumidores.

Já os empréstimos para crédito rural tiveram grande desaceleração desde $2013 \mathrm{com}$ crescimento inicial de 15,9\%, em 2013, e -5,6\% em 2017. Essa se deve à alta da taxa Selic, havendo assim aumento nas taxas de juros cobradas aos agricultores.

Para uma melhor comparação das concessões de crédito na instituição estudada no período de 2013 a 2017, foi elaborada a Figura 1.

Figura 1 - Principais modalidades de financiamento para pessoa física

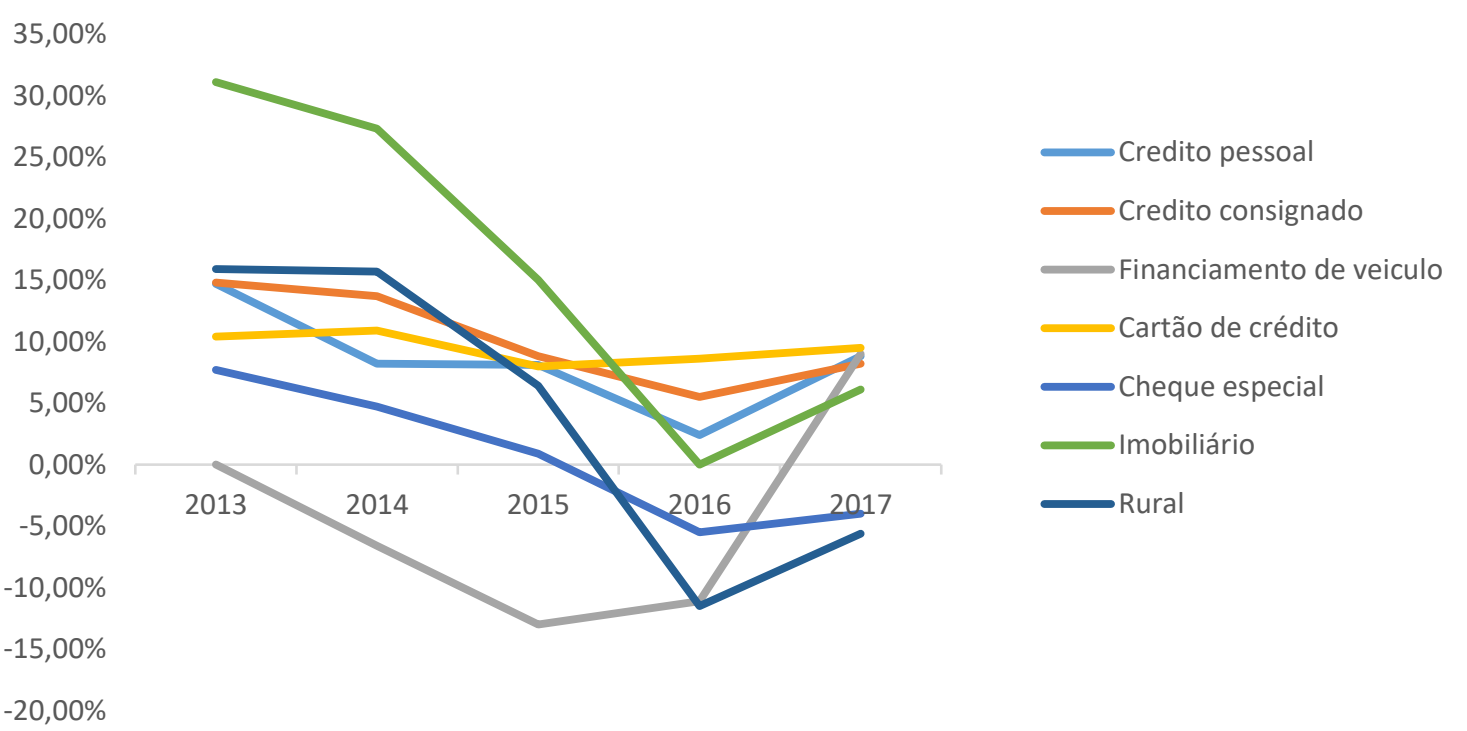

Fonte: Elaborado pela autora com base em relatórios do Banco estudado no período de 2013 a 2017.

Conforme a figura 1, é possível a observação de diversas mudanças no ambiente econômico no período de 2014 a 2016, entre elas, o comportamento da taxa de juros, o qual apresentou aumento, alta inflação, considerado reflexo da crise política e econômica. Segundo Oliveira (2010) esta situação remete pequenos investidores a almejarem níveis mais altos de rentabilidade em suas reservas financeiras, o que pode ser considerado um dos motivos que explicam a redução dos valores investidos em poupança, haja vista que essa é considerada a opção de investimento com menor rentabilidade entre as opções analisadas, e o aumento de investimento em LCl sendo que em 2014 aumentou 75,95\%, 2015 54,42\%, chegando à 24,66\% em 2017.

Em CDB nota-se um o aumento dos valores investidos, sendo no período de crise econômica, foi observado o maior aumento, em 2014 de 23,33\% e, em 2015 de 25,89\%. Segundo Lovato (2011), estes podem ser considerados os investimentos que estão entre os mais rentáveis em renda fixa, que dão ao investidor a opção de saber exatamente quanto seu dinheiro vai render ou optar por acompanhar as taxas de juros do mercado. Em linha semelhante, os principais resultados de Felipe et al. (2017), evidenciaram a constatação de indícios de mudanças do comportamento de escolha dos indivíduos em relação ao consumo de determinados produtos financeiros ao analisar os períodos pré e pós-crise do Suprime nos Estados Unidos.

A figura 2 apresenta um comparativo entre os principais investimentos da instituição pesquisada.

RGO - Revista Gestão Organizacional, Chapecó, v. 13, n. 2, p. 123-141, maio/ago. 2020. 
Figura 2 - Investimentos em uma instituição financeira privada, no período de 2013 a 2017

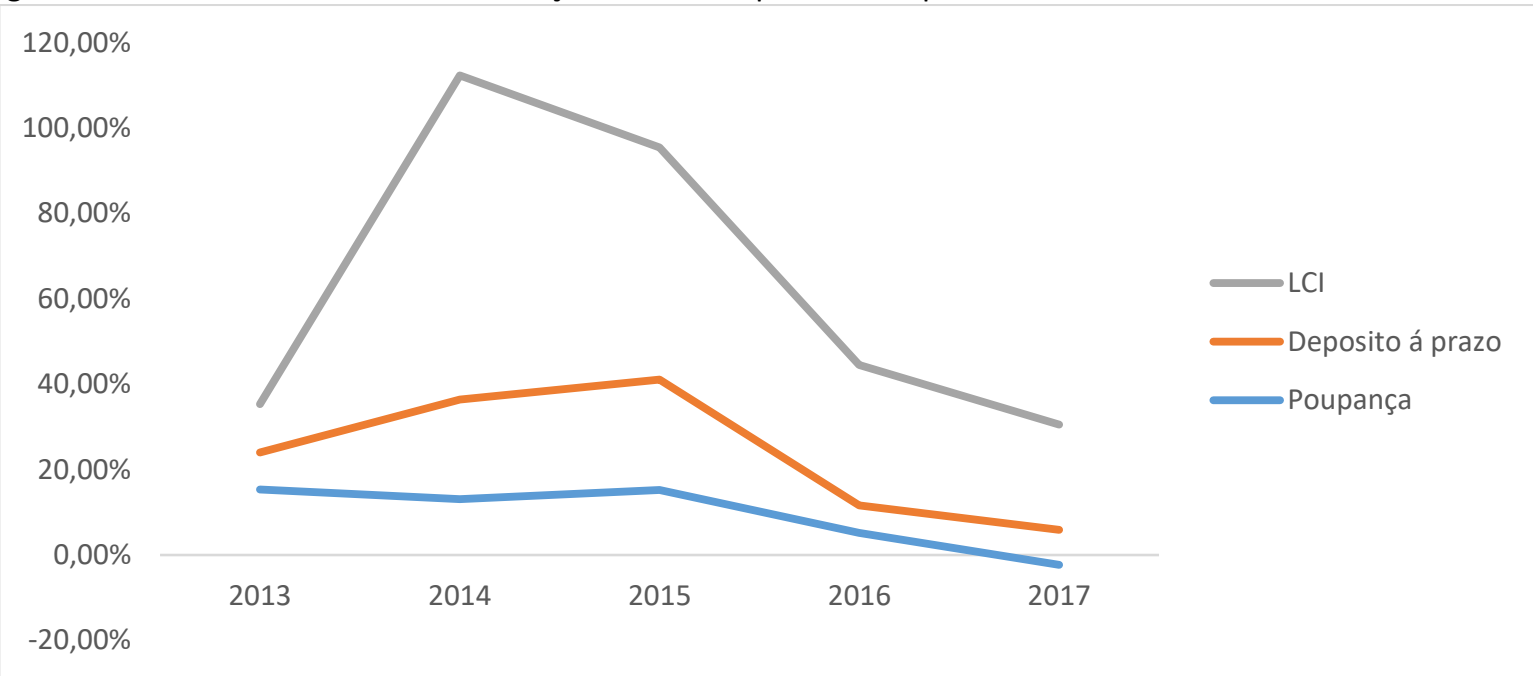

Fonte: Elaborado pela autora com base em relatórios do Banco estudado no período de 2013 a 2017

Na figura 2 é possível observar que no período de crise econômica, com a taxa Selic em alta, houve um grande crescimento nos investimentos, principalmente em $\mathrm{LCl}$ e CDB, devido a sua rentabilidade estar atrelada ao aumento da taxa Selic. Os achados evidenciados vão ao encontro do argumento de Said et al. (2015), ao afirmarem que momentos de crises podem induzir o aumento da aversão ao risco por parte dos investidores, o que ocasionaria recessão nos valores investidos. A queda nos valores aplicados em poupança pode ser explicada pelo baixo rendimento. No período pós crise, de 2015 e 2017, foi observada redução dos valores aplicados em $\mathrm{LCl}, \mathrm{CDB}$ e poupança, o que pode ter ocorrido em função da queda na taxa de juros, estando estes atrelados à Selic. É possível inferir, portanto, que pode ter havido maior procura por investimentos de renda variável como ações e fundos de investimentos que, apesar de apresentarem maior risco, maximizam os ganhos dos investidores.

As aplicações em renda fixa são afetadas, pois, a com a queda dos juros, o investidor buscar fazer uma maior diversificação dos seus investimentos e não apostar suas fichas em apenas um tipo um produto. Já em consulta ao site Globo.com, informam que de maneira geral, juros mais baixos estimulam as pessoas a investirem na chamada "economia real". Isso quer dizer que passa a ser mais interessante aplicar na expansão de negócios, melhorias na residência, com compra de equipamentos, reformas de residências, por exemplo, em vez de alocar dinheiro em aplicações financeiras.

\subsection{COMPARATIVO ENTRE A INSTITUIÇÃO ESTUDADA E OS DADOS DO CENÁRIO NACIONAL}

Após a análise das opções de investimento e crédito pessoa física em âmbito nacional, por meio dos dados obtidos em relatórios do BACEN e, posteriormente, os dados referentes à instituição pesquisada, buscou-se observar a comparação entre os créditos e financiamentos da pessoa física em uma instituição bancária privada e no âmbito nacional, conforme resultados expostos no Quadro 2. 
Quadro 2 - Comparação entre dados da instituição estudada e dados no Banco Central

\begin{tabular}{|c|c|c|c|c|c|c|c|c|c|c|}
\hline & \multirow{2}{*}{\multicolumn{2}{|c|}{$\begin{array}{c}\text { Ante rior à crise } \\
2013\end{array}$}} & \multicolumn{4}{|c|}{ Período de crise } & \multicolumn{4}{|c|}{ Posterior à crise } \\
\hline & & & \multicolumn{2}{|c|}{2014} & \multicolumn{2}{|c|}{2015} & \multicolumn{2}{|c|}{2016} & \multicolumn{2}{|c|}{2017} \\
\hline & $\begin{array}{l}\text { Inst. } \\
\text { Bancária } \\
\text { privada }\end{array}$ & $\begin{array}{l}\text { Cenário } \\
\text { Nacional }\end{array}$ & \begin{tabular}{|l|} 
Inst. \\
B ancária \\
privada
\end{tabular} & $\begin{array}{l}\text { Cenário } \\
\text { Nacional }\end{array}$ & $\begin{array}{l}\text { Inst. } \\
\text { Bancária } \\
\text { privada }\end{array}$ & $\begin{array}{c}\text { Cenário } \\
\text { Nacional }\end{array}$ & $\begin{array}{l}\text { Inst. } \\
\text { Bancária } \\
\text { privada }\end{array}$ & \begin{tabular}{c|} 
Cenário \\
Nacional
\end{tabular} & $\begin{array}{l}\text { Inst. } \\
\text { Bancária } \\
\text { privada }\end{array}$ & $\begin{array}{c}\text { Cenário } \\
\text { Nacional }\end{array}$ \\
\hline \multicolumn{11}{|l|}{$\begin{array}{l}\text { Crédito à } \\
\text { pessoa Física: }\end{array}$} \\
\hline Credito pessoal & + & + & + & + & + & + & + & + & + & - \\
\hline $\begin{array}{l}\text { Credito } \\
\text { consignado }\end{array}$ & + & + & + & + & + & + & + & + & + & + \\
\hline $\begin{array}{l}\text { Financiamento de } \\
\text { veiculo }\end{array}$ & - & - & - & - & - & - & - & - & + & - \\
\hline Cartão de crédito & + & + & + & + & + & + & + & + & + & + \\
\hline Cheque especial & + & + & + & + & + & + & - & - & - & - \\
\hline Imobiliário & + & + & + & + & + & + & + & + & + & + \\
\hline Rural & + & + & + & + & + & + & - & + & - & + \\
\hline \multicolumn{11}{|l|}{$\begin{array}{l}\text { Investimentos a } \\
\text { pessoa física: }\end{array}$} \\
\hline Poupança & + & + & + & + & + & - & + & + & - & + \\
\hline Deposito á prazo & + & + & + & - & + & + & + & + & + & + \\
\hline LCI & + & + & + & + & + & + & + & - & + & + \\
\hline
\end{tabular}

Fonte: Elaborado pela autora com base em relatórios do Banco Central e da Instituição estudada

Conforme apresentado no quadro 2, nota-se que a instituição estudada, em grande parte das modalidades analisadas, tanto de investimento como de crédito concedido à pessoa física, acompanhou o comportamento do cenário nacional, se diferenciado em poucos pontos. Mais especificamente, no período posterior crise, a instituição estudada não acompanhou o cenário nacional na concessão do crédito rural, no qual o cenário nacional teve crescimento e na instituição estudada, contrariamente, apresentou queda na concessão deste financiamento.

Essa diferenciação pode ter como explicação, segundo o Jornal do Comércio (2017), o fato de que a concessão do crédito rural está tradicionalmente mais direcionada aos Bancos públicos e às cooperativas de crédito no Rio Grande do Sul. Em relação aos investimentos, em 2017, a instituição privada bancária apresentou comportamento oposto em relação aos depósitos em poupança, na qual houve a diminuição de destes na instituição estudada e, aumento de depósitos no cenário nacional.

Conforme esperado a priori, os resultados evidenciaram que, em período de crise, quando a taxa Selic está em alta, os investimentos apresentaram-se alavancados devido à, sua maior rentabilidade, entretendo os financiamentos obtiveram redução em sua concessão, devido á altas taxas de juros. Já no período pós-crise econômica, com a redução da taxa Selic, os investimentos tiveram redução dos valores aplicados e, as modalidades de financiamento tiveram maior concessão ao crédito.

\section{CONSIDERAÇÕES FINAIS}

A economia brasileira passou, recentemente, por momentos de insegurança e instabilidade econômica, trazidos à tona pelo cenário político, elevando as taxas de juros e a inflação, a qual acarretou alterações para a atividade econômica brasileira como um todo. Tendo por base os efeitos da crise, especificamente das alterações na taxa de juros, o presente estudo teve como objetivo identificar o comportamento da taxa Selic e sua relação com os investimentos e financiamentos pessoa física no período pós-crise econômica em uma 
instituição bancária privada. Para seu alcance, foi realizada uma pesquisa de cunho quantitativo e descritivo por meio da comparação dos dados obtidos para a empresa estudada aos dados relacionados ao cenário nacional.

A análise de dados permitiu identificar que, especificamente no cenário nacional, houve redução da concessão de crédito no período de crise econômica, contrariamente, nos investimentos foi observado crescimento considerável, visto que a taxa Selic estava em alta, a qual serve como referência para todas as outras taxas de juros praticadas no mercado e também, sendo ainda considerada referência na determinação dos rendimentos nos investimentos. De maneira contrária, o período que compreende informações pós-crise econômica apresentou comportamento distinto. Por meio da análise do período em que houve redução da taxa Selic foi identificado crescimento na concessão de crédito e diminuição dos investimentos, pois com a redução da taxa Selic ocorreu menor cobrança da taxa de juros pelas instituições bancárias na concessão de financiamentos e ocorreu menor rentabilidade nos investimentos.

A segunda etapa da pesquisa, consistiu na análise de dados da instituição bancária privada, evidenciando redução das concessões de crédito no período de crise, o qual deve-se a alta da taxa Selic praticada e também às altas taxas de juros cobradas, já os investimentos apresentaram crescimento considerável, influenciados pelo aumento da rentabilidade, ocasionado pela elevação da taxa de juros. No período pós-crise econômica, de maneira contrária, a redução da taxa Selic ocasionou redução dos investimentos, devido a rentabilidade mais baixa e, aumento na concessão de crédito em função da redução dos juros cobrados pelo banco para emprestar recursos.

Em suma, é possível inferir que o período entre os anos de 2014 a 2016 foi marcado pela manutenção de elevadas taxas de juros, ocasionando assim, aumento nos juros cobrados pelas instituições nas concessões de crédito. Neste cenário, nota-se que a concessão de crédito da instituição privada foi semelhante ao do cenário nacional se comparado ao relatório nacional de concessão de crédito fornecido pelo Banco Central. Dentre as opções analisadas, somente o crédito rural não apresentou o mesmo comportamento, havendo crescimento desta modalidade no cenário nacional e, na instituição privada, decréscimo na concessão deste. Além disso, pode-se inferir que, com a taxa Selic em alta no período de crise econômica (2014 e 2015) os investimentos tornaram-se mais atrativos economicamente. Os dados ainda evidenciaram que, exceto pela poupança, que em 2017 apresentou decréscimo dos valores depositados, os investimentos realizados na instituição analisada acompanharam o crescimento observado no cenário nacional.

Embora os resultados tenham demonstrado de forma importante, a influência da taxa Selic em investimento e financiamento da pessoa física na instituição estudada, cabe ressaltar alguns aspectos que limitaram tanto as análises quanto, as considerações mais assertivas na pesquisa. Entre elas, citam-se as poucas evidências empíricas e teóricas acerca da recente crise econômica do Brasil, o que dificultou a discussão de alguns resultados e não permitiu inferências assertivas. Além disso, dado o largo campo de análise, como delineamento de pesquisas futuras, sugere-se a elaboração de pesquisas cujo foco sejam as diferentes taxas de juros que influenciam os investimentos e financiamentos da pessoa física, bem como maiores estudos sobre a recente crise econômica e política do Brasil.

\section{REFERÊNCIAS}

ASSAF A. N. Mercado financeiro, 10. ed. São Paulo: Atlas, 2011. 
; LIMA F. G. Curso de administração financeira. 2. ed. São Paulo: Atlas, 2011.

ADLAS D. C. A relação entre o comportamento da taxa básica de juros e o mercado de crédito. 2012. Monografia (Bacharelado em Ciências Contábeis) - Faculdade de Tecnologia e Ciências Sociais Aplicadas, Brasília, DF, 2012.

BARBOSA FILHO, F. H. A crise econômica de 2014/2017. Caderno de Estudos Avançados, São Paulo, v. 31, n. 89, p. 1-15, jan./ 2017. DOI: https://doi.org/10.1590/s010340142017.31890006.

BANCO CENTRAL, disponível em: <http://www.agricultura.gov.br/noticias/contratacaodecredito-rural-cresce-12-4-e-alcanca-r-92-1-bilhoes>. Acesso em: 06 mai. 2018.

CARVALHO, N. M. Evidenciação de derivativos. Caderno de Estudos Avançados, São Paulo, v. 20, p. 01-16, jan./abr. 1999. DOI: https://doi.org/10.1590/S1413-92511999000100003.

CETIP. Letra de Crédito Imobiliário. Recursos aplicados são direcionados para financiamentos habitacionais. Disponível em: <https://www.cetip.com.br/captacaobancaria/lci>. Acesso em: 12 set. 2017.

DIAS, H. L. S. As alternativas de investimento em renda fixa para pessoa física: Uma análise de risco e retorno do tesouro direto, o CDI e a caderneta de poupança entre 2002 e 2015. (2016). Monografia (Bacharelado em Ciências Econômicas) - Universidade Federal de Santa Catarina, Florianópolis, SC, 2016.

FELIPE, I. J. S.; ERNEL, M. D. A.; CASSIUS, L. F. P.; SILVA, W. M. Efeito da crise econômica sobre escolhas de ativos para investimentos pessoais. Revista de Administração

Contemporânea, Rio de Janeiro, v. 21, Edição Especial FCG, art. 5, p. 84-109, abr./ 2017. DOI: http://dx.doi.org/10.1590/1982-7849rac2017160087.

FORTUNA, E. Mercado Financeiro: produtos e serviços. 16. ed. Rio de Janeiro: Qualitymark, 2005.

GIL, A. C. Como elaborar projetos de pesquisa. $4^{\circ}$ ed. São Paulo: Atlas, 2002.

GLOBO.COM, Por que os juros do crédito imobiliário não acompanham a queda da taxa Selic. Disponível em: <https://g1.globo.com/economia/noticia/por-que-os-juros-do-creditoimobiliario-nao-acompanham-o-ritmo-de-queda-da-selic.ghtml>.

Acesso em: 06 mai. 2018

GLOBO.COM, Como a queda dos juros ajudou a economia até agora. Disponível em: <https://g1.globo.com/economia/noticia/como-a-queda-dos-juros-ajudou-a-eco nomiaateagora.ghtml>. Acesso em: 19 mai. 2018

HAIR JR., J. F. Fundamentos de métodos de pesquisa em administração. Porto Alegre: Bookman, 2005. 
HOFFMANN, A., POST, T.; PENNINGS, J. Individual investor perceptions and behavior during the financial crisis. Journal of Banking \& Finance, v. 37, n. 1, p. 60-74, 2013. DOI:

http://dx.doi.org/10.1016/j.jbankfin.2012.08.007.

HORVATH, J. Business cycles, informal economy, and interest rates in emerging countries. Journal of Macroeconomics, v. 55, p. 96-116, mar. 2018. DOI: https://doi.org/10.1016/j.jmacro.2017.10.002.

HUBERT, S. O tonel das danaides: consumo a crédito, superendividamento e a espoliação dos vulneráveis no Brasil contemporâneo. (2016). Dissertação (Mestrado em Sociologia) Programa de Pós-Graduação em Sociologia, Universidade Federal do Rio Grande do Sul, Porto Alegre, RS, 2016.

JORNAL DO COMÉRCIO, o Jornal da Economia e negócios do RS. Bancos privados investem na disputa do crédito rural. Disponível em:

<http://www.jornaldocomercio.com/_conteudo/2017/05/economia/562518-bancosprivados-investem-na-disputa-do-credito-rural.html>. Acesso em: 11 jun. 2018.

KERR R. B. Mercado financeiro e de capitas. São Paulo: Pearson Prentice, 2011.

KRINGGER, G.; PANICHI L. M. A crise econômica no Brasil: influências nos indicadores financeiros das sociedades anônimas de capital aberto. Revista online Faculdade de Ciências Econômicas: Repositório Digital da UFRGS, Porto Alegre, v. 1, p. 3-22, jan./jun. 2016.

LIMA, R. Alguns determinantes macroeconômicos da taxa de juros Selic no Brasil: uma análise econométrica no período de agosto de 1994 a março de 2015. (2015). Monografia (Bacharelado em Ciências Econômicas com ênfase em Controladoria) - Universidade Federal de Alfenas, Varginha, MG, 2015.

LOVATO, B. N. Finanças pessoais: Investimentos de renda fixa e renda variável. Monografia (Bacharelado em Ciências Contábeis) - Universidade Federal de Santa Catarina, Florianópolis, SC. 2011.

LUQUET, M. Guia Valor Econômico de finanças pessoais. 2 ed. São Paulo: Editora Globo Livros, 2007.

MALHOTRA, N. K. Pesquisa de marketing: uma orientação aplicada. $4^{\circ}$ ed. Porto Alegre: Bookman, 2006.

MELLAGI FILHO, A.; ISHIKAWA, S. Mercado financeiro e de capitais. $2^{\circ}$ ed. São Paulo: Atlas, 2003.

NAKANO, Y. O regime monetário, a dívida pública e a alta taxa de juros. Revista Conjuntura Econômica, Rio de Janeiro, v. 59, n. 11, p. 10-12, 2005.

NASSIF, A. An analysis of Brazil's economy situation: 2014-2017, the short-term outlook and policy alternatives. Brazilian Keynesian Review, v. 3, n. 1, p. 95-108, 1sem./2017. 
DOI: https://doi.org/10.33834/bkr.v3i1.106.

OLIVEIRA, M. J. S. Variação da taxa Selic e a rentabilidade de fundos de investimentos referenciados: uma análise comparativa do período de 2013 a 2016. Brazilian Journal do Development, Curitiba, v. 4, n. 4, p. 1449-1463, jul./set. 2018.

OLIVEIRA, N. C. Métodos utilizados para análise de crédito de pessoa física nas instituições financeiras e sua relação com o índice de inadimplência. (2010). Monografia (Bacharelado em Ciências Contábeis) - Instituto de Ciências Econômicas e Gerenciais, Pontifícia Universidade Católica de Minas Gerais, Belo horizonte, MG, 2010.

OREIRO, J. L. A grande recessão brasileira: diagnóstico e uma agenda da política econômica. Estudos Avançados, São Paulo, v. 31, n. 89, p. 75-89, jan./abr. 2017. DOI: https://doi.org/10.1590/s0103-40142017.31890009.

PASSOS, F. V. Análise da relação entre Taxa Selic e Crédito Bancário em 2000-2007. (2007). Monografia (Curso de Ciências Econômicas) - Universidade Federal de Santa Catarina, Florianópolis, SC, 2007.

PAULA L. F.; PIRES, M. Crise e perspectivas para a economia brasileira. Estudos Avançados, São Paulo, v. 31, n. 89, p. 125-144, jan./abr. 2017. DOI: https://doi.org/10.1590/s010340142017.31890013.

PIGNATA, F. A.; CARVALHO, D. O.. Efeitos da crise econômica no Brasil em 2015. Diálogos Acadêmicos, São Paulo, v. 09, n. 2, p. 04-18, jul./dez. 2015.

PORTAL BRASIL, Bancos anunciam redução das taxas de juros após corte da Selic. Disponível em: <http://www.brasil.gov.br/economia-e-emprego/2017/01/bancos-cortam-juros-paraclientes-apos-queda-na-selic>. Acesso em: 19 ago. 2017.

SAID, F.; AFZAL, U.; TURNER, G. Risk taking and risk learning after a rare event: evidence from a field experiment in Pakistan. Journal of Economic Behavior and Organization, v. 118, p. 67-183, out. 2015. DOI: https://doi.org/10.1016/j.jebo.2015.03.001.

SANT'ANNA, A. A.; BORÇA JUNIOR, G. R.; ARAUJO, P. Q. Mercado de crédito no Brasil: evolução recente e o papel do BNDES (2004-2008). Revista do BNDES, Rio de janeiro, v. 16, n. 31, p. 41-60, jun./ 2009.

SILVA, J. P. Administração de crédito e previsão de insolvência. São Paulo: Atlas, 2008.

VARTANIAN, P. R.; GARBE, H. S. The Brazilian economic crisis during the period 2014-2016: is there precedence of internal or external factors? Journal of International and Global Economic Studies, v. 12, n. 1, p. 66-86, jun./ 2019. 